\title{
Survival and immune response of the Chagas vector Meccus pallidipennis (Hemiptera: Reduviidae) against two entomopathogenic fungi, Metarhizium anisopliae and Isaria fumosorosea
}

\author{
A. Laura Flores-Villegas ${ }^{1}$, Margarita Cabrera-Bravo ${ }^{1}$, Conchita Toriello ${ }^{1}$, Martha I. Bucio-Torres ${ }^{1}$, \\ Paz María Salazar-Schettino ${ }^{1^{*}}$ and Alex Córdoba-Aguilar ${ }^{2^{*}}$ (D)
}

\begin{abstract}
Background: Chagas disease is a key health problem in Latin America and is caused and transmitted by Trypanosoma cruzi and triatomine bugs, respectively. Control of triatomines has largely relied on the use pyrethroids, which has proved to be ineffective in the long term. Alternatively, the use of entomopathogenic fungi has been implemented to control triatomine bugs. These fungi are highly efficient as they induce a reduction in immune response on insects. Meccus pallidipennis is the main triatomine vector of Chagas disease in Mexico. In this work we investigated the effects of two entomopathogenic fungi, Metarhizium anisopliae and Isaria fumosorosea, on M. pallidipennis nymphs in terms of insect survival and immune response.
\end{abstract}

Methods: We had an infected and a control group for each fungal species and assessed: a) insect survival during 30 days; and, b) phenoloxidase (PO) and prophenoloxidase (proPO; two key traits in insect immune response) at 24, 48, 96 and $144 \mathrm{~h}$. For survival we used Kaplan-Meier survival analysis while for immune response we used factorial, repeatedmeasures ANOVA for each fungal species.

Results: Animals treated with M. anisopliae died sooner than animals treated with I. fumosorosea. Infected animals showed lower PO and proPO values than sham individuals, with a clear decrease in these parameters at $24 \mathrm{~h}$ with no further changes after this time.

Conclusions: Our study widens the possibility of entomopathogenic fungi being used for triatomine control. The negative effect on $\mathrm{PO}$ and $\mathrm{proPO}$ seems mediated by a down-regulation of the triatomine immune response.

Keywords: Chagas disease, Meccus pallidipennis, Entomopathogenic fungi, Survival, Phenoloxidase, Prophenoloxidase

\footnotetext{
*Correspondence: pazmar@unam.mx; acordoba@iecologia.unam.mx

'Departamento de Microbiología y Parasitología, Facultad de Medicina,

Universidad Nacional Autónoma de México, México, DF, Mexico

${ }^{2}$ Departamento de Ecología Evolutiva, Instituto de Ecología, Universidad

Nacional Autónoma de México, Apdo. P. 70-275, Circuito Exterior, Ciudad

Universitaria, 04510 Coyoacán, Distrito Federal, Mexico
} 


\section{Background}

Chagas disease is caused by the protozoan Trypanosoma cruzi and is considered endemic from Mexico to Argentina [1]. The main transmission source is vectorial, through insect bugs of the subfamily Triatominae (Hemiptera: Reduviidae) [2]. For the case of Mexico, Meccus pallidipennis is responsible of approximately $74 \%$ of vectorial transmission (Martínez-Ibarra et al. [3]). The biology of $M$. pallidipennis explains such high transmission rate: a) a wide distribution in Mexico [4,5] b) its relatively high abundance compared to other triatomines [6] c) its peridomestic nature, meaning close contact with humans [6] d) it is one of the triatomines with the highest T. cruzi infection rates [7]; and e) its capacity as highly efficient vector in terms of egg incubation and hatching time, egg-to-adult mortality, oviposition rate and post-feeding defecation times [8].

Given the risk that $M$. pallidipennis implies for $T$. cruzi transmission, there have been several efforts to control it. One of these is the use of synthetic pyrethroids such as bifenthrin, cyfluthrin and deltamethrin insecticides. However, these pyrethroids are not reliable given the high bug re-infestation in dwellings after pyrethroid spraying $[9,10]$, which is associated with insecticide resistance $[11,12]$. Although some other control methodologies have been proposed and/or explored (e.g. using genetically-modified endosymbiont bacteria that impede T. cruzi development [13], using natural predators [14]), possibly more than one control action is needed [15]. Here we explored the use of two entomopathogenic fungi, Metarhizium anisopliae (Hypocreales: Clavicipitaceae) and Isaria fumosorosea (Hypocreales: Cordycipitaceae), against $M$. pallidipennis nymphs. Use of these fungi has been highly successful for controlling different insect pests and vectors such as Asian tiger mosquitoes Aedes albopictus [16], cattle ticks Rhipicephalus microplus [17], Asian citrus psyllids Diaphorina citri [18] and diamondback moth Plutella xylostella [19]. As a matter of fact, several strains of $M$. anisopliae and I. fumosorosea, that are highly efficient to kill triatomines, have been identified [20-23]. Thus, entomopathogenic fungi seem a viable route for triatomine biological control [12, 23-25].

The mechanism that makes entomopathogenic fungi so successful during insect attack, starts with the conidium contact with the insect cuticle [26]. During this, the fungus adheres, penetrates, disseminates and exits the insect body [27]. Once inside, the fungus evades the insect's immune system by: 1) enzyme (e.g. proteases and chitinases) development that degrades the insect cuticle; 2) development of blastospores and hyphal bodies in the hemolymph which inhibit insect immune response; and 3) production of secondary toxic metabolites such as destruxins and beauvericins [28]. However, perhaps the largest attribute of entomopathogenic fungi as a vector and pest control relies on their immunosuppressive action. In support of these, several studies have found that two key insect immune players, phenoloxidase (PO) and, its precursor, prophenoloxidase (proPO), become downregulated during fungal infection in some, but not all, insect species [29-31]. It is known that during the course of infection, insects make use of $\mathrm{PO}$ and proPO against a plethora of pathogens $[32,33]$. The enzymatic process from proPO to $\mathrm{PO}$ is regulated by a complex proteolytic cascade, which is activated by the recognition of cell wall components of fungi and other pathogens [32]. Furthermore, PO gives rise to cuticle sclerotization and wound repair but also promotes melanine biosynthesis during the formation of nodules and encapsulation of pathogens [34, 35]. Although it is unclear how PO and proPO activity is inhibited, one hypothesis is that fungal destruxins destroy those proteins present in insect cells responsible for proPO production [36, 37].

The main aim of this study was to test the efficiency of two entomopathogenic fungi, Metarhizium anisopliae and Isaria fumosorosea, to control M. pallidipennis nymphs. For this, first we infected bugs using each fungal species individually and assessed survival. Then, to understand the physiological mechanism underlying fungal infection, we recorded the activity of $\mathrm{PO}$ and proPO using repeated time measures of the same individual.

\section{Methods}

\section{Insects}

We used 5th stage nymphs of $M$. pallidipennis, from a colony maintained in the insectary of the Biology of Parasites, Microbiology and Parasitology Department, Faculty of Medicine, Universidad Nacional Autónoma de México. This colony was established in 1998 from insect individuals collected from Oaxtepec village (18 $54^{\prime}$ $\left.23^{\prime \prime} \mathrm{N}, 98^{\circ} 58^{\prime} 13^{\prime \prime} \mathrm{W}\right)$, state of Morelos, Mexico. Insects were maintained under controlled conditions of $60 \%$ relative humidity, $28{ }^{\circ} \mathrm{C}$, and $12 / 12 \mathrm{~h}$ light/dark cycles at the laboratory.

\section{Nymph infection \\ Fungi}

We used monosporic cultures of $M$. anisopliae EH-473/4 and I. fumosorosea EH-511/3 strains whose insect virulence, pheno-and genotypic characterization and safety for mammals are well known [38-40]. These fungi are part of the culture Collection of the Basic Mycology Laboratory, Microbiology and Parasitology Department, Faculty of Medicine, Universidad Nacional Autónoma de México, registered in the "World Federation of Culture Collections" (WFCC) as BMFM-UNAM 834. The original fungal strains were obtained from the "Colección de Hongos Entomopatógenos (CHE)" from the Centro Nacional de Referencia de Control Biológico (CNRCB), Colima City, Mexico. M. anisopliae was isolated in 1994, from 
Aeneolamia sp. (Hemiptera: Cercopidae), from a sugarcane crop in San Luis Potosi city, Mexico. The label of $M$. anisopliae at CNRCB is CHE-CNRCB 227. The other fungus, I. fumosorosea was isolated in 1994 from Bemisia sp. (Hemiptera: Aleyrodidae) from a watermelon crop in Colima, Mexico. The label of I. fumosorosea at CNRCB is CHE-CNRCB 304. Fungi were previously cultivated in potato dextrose agar (PDA, g/l: $300 \mathrm{~g}$ of white potato, $20 \mathrm{~g}$ of dextrose, $15 \mathrm{~g}$ of agar $\left(\mathrm{BIOXON}^{\circ}\right.$, México) and then incubated at $28^{\circ} \mathrm{C}$ for eight days [41].

Conidial suspension. The conidia were produced in PDA medium cultures and incubated at $28{ }^{\circ} \mathrm{C}$ for 7 days. After incubation, conidia were obtained using $3 \mathrm{ml}$ of $0.5 \%$ Tween 80 . This suspension was kept on ice throughout the bioassay, homogenized and two dilutions were performed: 1:10 and 1:100. The number of conidia was counted in a Neubauer chamber and the suspension was adjusted to obtain a final concentration of $1 \times 10^{7}$ conidia/ml for the infection procedure. The whole procedure was performed in a laminar flow hood [42].

\section{Survival assessment}

\section{Infection procedure and infected group}

We applied $30 \mu \mathrm{l}$ from a suspension of $1 \times 10^{7}$ conidia/ml of M. anisopliae or I. fumosorosea on each nymph's pronotum. Each nymph was placed individually in a sterile plastic Petri dish with sterile filter paper and was incubated at $28{ }^{\circ} \mathrm{C}$ with a $12 / 12 \mathrm{~h}$ light/dark cycle. After $24 \mathrm{~h}$, all infected nymphs were transferred to $1 \%$ agar-water (to provide appropriate humidity conditions for fungal growth) in plastic Petri dishes $(100 \times 15 \mathrm{~mm})$ and were again incubated using a Precision $818^{\circ}$ incubator at $28{ }^{\circ} \mathrm{C}$ and $80 \%$ relative humidity for one month. We corroborated that the infection took place by assessing presence of hyphae and/or mycelium on the insect, and we recorded the number of dead insects daily [40,42, 43]. We had three criteria to assess that an insect was dead due to fungal infection: a) signs of mycelium presence on the cuticle (by direct observation under a stereoscopic microscope, Olympus SZ40); b) presence of fungal structures inside the insect using imprints on the day when dead insects were recorded; and c) motionless insects. Furthermore, we took fungal samples from nine infected insects of each fungus. This was done by taking some sporulating fungi emerging from the insect cuticle, using an inoculating loop under a flow hood. Fungal samples were cultivated in PDA cultures, to corroborate the micro- and macroscopic characteristics of each infecting fungal species. For imprints, the insect cuticle surface was cleaned using $70 \%$ ethanol and $40 \%$ sodium hypochlorite to remove potential contaminants [42]. Subsequently, a longitudinal (from head to posterior end) cut was gently made using scissors and the cuticle was removed. A drop of blue cotton was then placed on the internal area of the cuticle, and this structure was placed on a slide, covered with a coverslip and sealed with nail varnish to be observed under a microscope at 40x. Each evaluated group had 10 insects with 5 replicates for each fungus, i.e. 50 insects per fungal strain infection.

\section{Sham group}

We applied $30 \mu \mathrm{l}$ of $0.5 \%$ Tween 80 on each nymph's pronotum. Each animal was then moved to a Plastic Petri dish with sterile filter paper and was incubated at $28{ }^{\circ} \mathrm{C}$ with a $12 / 12 \mathrm{~h} \mathrm{light/dark} \mathrm{cycle.} \mathrm{Except} \mathrm{for} \mathrm{the} \mathrm{fungal}$ infections, this sham group was treated under the same conditions as the infected groups: $24 \mathrm{~h}$ after applying $30 \mu \mathrm{l}$ of $0.5 \%$ Tween 80 , all insects were transferred to agarwater ( $1 \%$; again to provide humidity conditions for fungal growth) in plastic petri dishes $(100 \times 15 \mathrm{~mm})$ (see [43]) and were incubated using a Precision $818^{\circ}$ equipment at $28{ }^{\circ} \mathrm{C}$ and $80 \%$ relative humidity for one month. Similar to the infected group, mortality of sham insects was recorded daily for one month. To assess whether an insect was dead, we also applied the three criteria expressed above. Similar to the infected groups, we used 10 insects with 5 replicates for each fungus, i. e. 50 insects for each fungal strain.

\section{Negative effects of fungal infection on $\mathrm{PO}$ and proPO}

We used the same rationale of infection and incubation for those animals described above for the survival experiment. However, rather than assessing survival, we collected hemolymph from both groups every 24, 48, 96 and $144 \mathrm{~h}$ after the infection for both fungal species.

\section{Hemolymph extraction}

Using a $1 \mathrm{ml}$ micro syringe, we punctured the insect membrane that separates the coxa and trochanter of one of the posterior legs [44], and gently pushed the abdomen. The emerging hemolymph was then collected with a $10 \mu \mathrm{l}$ micropipette. Hemolymph was mixed with PBS pH $7.21 \times$ $2.9 \mathrm{~g}$ of $\mathrm{Na}_{2} \mathrm{HPO}_{4} .12 \mathrm{H}_{2} \mathrm{O}, 0.2 \mathrm{~g}$ of $\mathrm{KH}_{2} \mathrm{PO}_{4}, 0.2 \mathrm{~g}$ of $\mathrm{KCl}$, $8.0 \mathrm{~g}$ of $\mathrm{NaCl}$ and deionized water, in a proportion of 1:2.

\section{Protein concentration}

For protein quantification and standardization in our samples, we used the Pierce method with the BCA commercial kit (Thermo Fisher Scientific, Rockford, Illinois). For this, in each of 96 microwells of a plate (Costar 96; Corning, New York, New York) we placed $10 \mu \mathrm{l}$ of hemolymph, $40 \mu \mathrm{l}$ of PBS pH $7.21 \mathrm{X}$ and $150 \mu \mathrm{l}$ of the Pierce re-agent. We used $2 \mathrm{mg} / \mathrm{ml}$ albumin to obtain a standard curve. The plate was covered with foil and was incubated at $37^{\circ} \mathrm{C}$ for $30 \mathrm{~min}$. Absorbance was measured in an ELISA plate reader (ELX 800, Biotek) at $562 \mathrm{~nm}$. Protein content was adjusted to $10 \mu \mathrm{g}$ of protein to record $\mathrm{PO}$ and proPO activity [45]. 


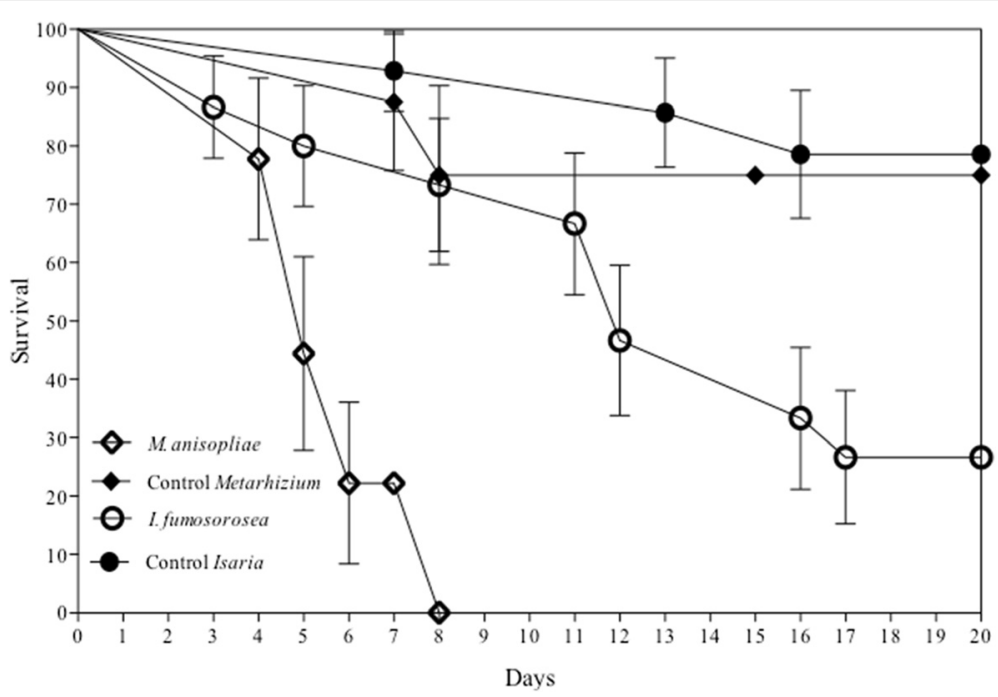

Fig. 1 Survival of fifth instar nymphs of Mccus pallidipennis infected with M. anisopliae (EH- 473/4), I. fumosorosea (EH- 511/3) and their control groups

\section{PO activity}

PO activity levels were quantified spectrophotometrically through catalytic conversion of L-dopa 3, 4-dihydroxi-Lphenylalanine (colorless) to dopachrome (brown-red) [46]. Again using a 96 microwell plate, we added $10 \mu \mathrm{g}$ of protein of each sample contained in $100 \mu \mathrm{l}$ of PBS. To start PO activation, we added $100 \mu \mathrm{l}$ of the L-DOPA substrate to a $4 \mathrm{mg} / \mathrm{ml}$ concentration. The plate was incubated at $37{ }^{\circ} \mathrm{C}$ for $20 \mathrm{~min}$ in the dark. After this 20min period, readings were taken with an ELISA plate reader (ELX 800, Biotek) at $490 \mathrm{~nm}$ each $5 \mathrm{~min}$ for one hour (giving a total of 12 readings). As blanks we used $100 \mu \mathrm{l}$ of PBS with $100 \mu \mathrm{l}$ of L-Dopa. PO readings were obtained in different time periods: after 24, 48, 96 and $144 \mathrm{~h}$. PO activity was expressed as enzyme units (U), where $1 \mathrm{U}$ is the enzyme amount which produces $1 \mu \mathrm{mol}$ of dopachrome (product) per minute [47].

\section{proPO activity}

proPO activity was recorded via an artificial activation with $\alpha$-chymotrypsin [46]. We used $1 \mu \mathrm{g} / \mathrm{ml}$ of $\alpha$-chymotrypsin $($ Sigma $)$. Using the same 96 microwell plate described

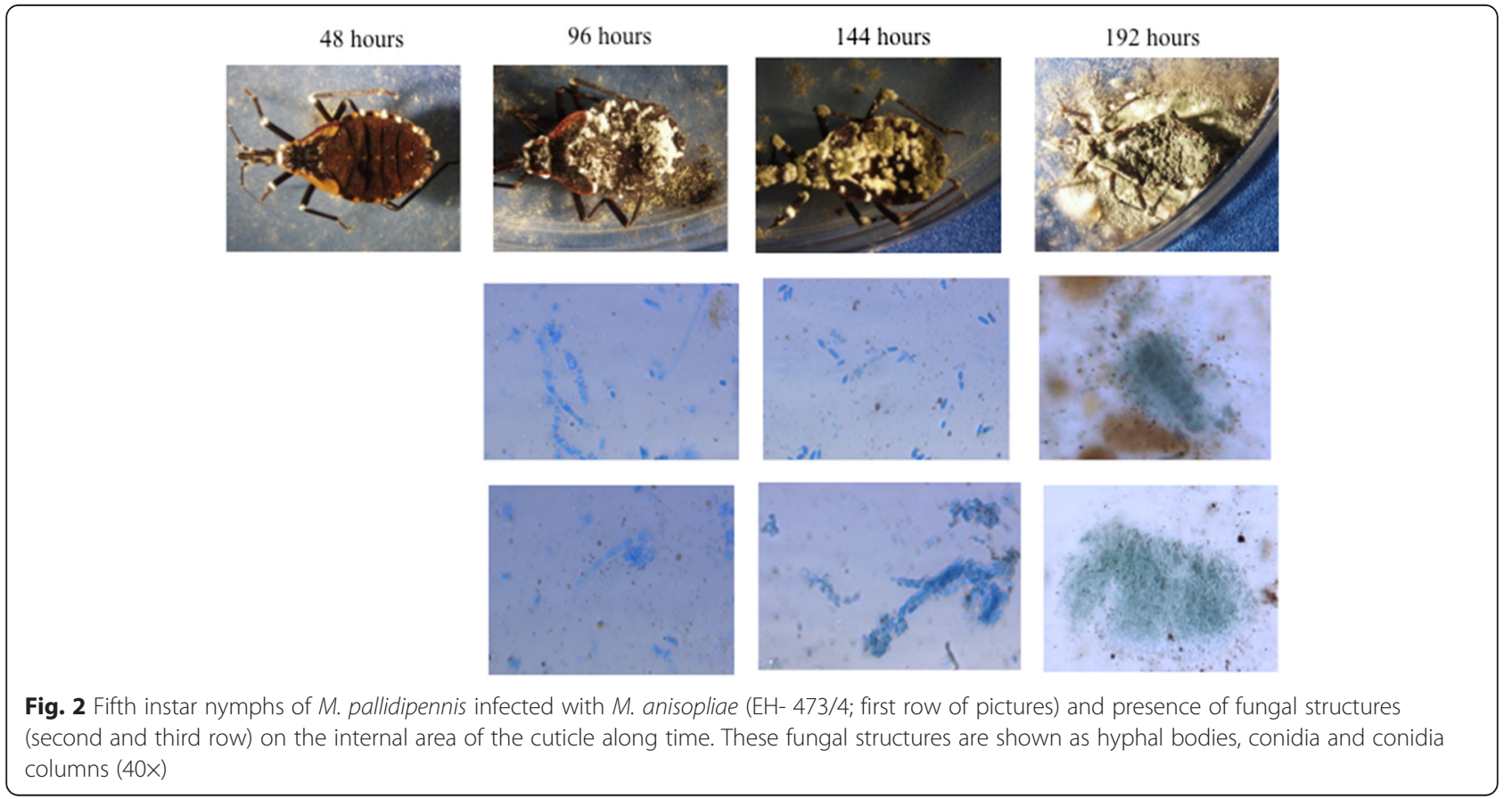




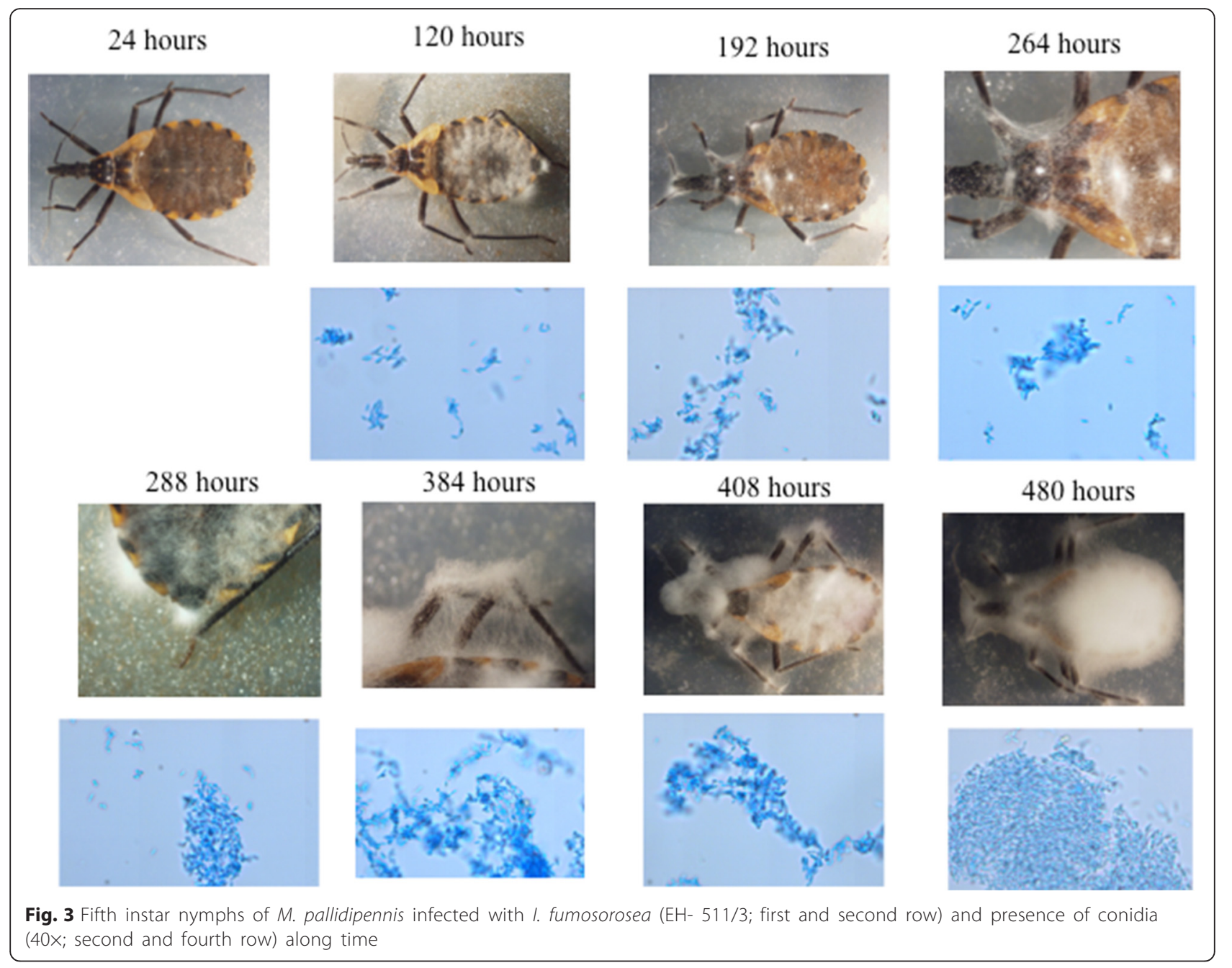

above, we added $45 \mu \mathrm{l}$ of PBS, $20 \mu \mathrm{l}$ of hemolymph sample and $5 \mu \mathrm{l}$ of $\alpha$ - chymotrypsin. This mixture was incubated at $37{ }^{\circ} \mathrm{C}$ for $20 \mathrm{~min}$ in the dark. After this 20 -min period, $130 \mu \mathrm{l}$ of L-Dopa was added, and the resulting readings were recorded at $490 \mathrm{~nm}$, each $5 \mathrm{~min}$ for one hour (giving a total of 12 readings). As blanks, we used $65 \mu$ of PBS with $130 \mu \mathrm{l}$ of L-Dopa. proPO readings were obtained in different time periods: after 24, 48, 96 and $144 \mathrm{~h}$. To record specific proPO activity, we did the same as for $\mathrm{PO}$ described above.

\section{Statistical analyses}

We used Kaplan-Meier analysis for survival. Average survival time as well as risk ratio index were analyzed using a Log-rank (Mantel-Cox) test. For analyzing the effect of treatment on PO and proPO, we used four factorial, repeated-measures ANOVA for each fungal species, with time of $\mathrm{PO}$ and proPO assessment as the repeated measure and treatment (experimental, sham) as the between-group variable. Previously, and to fulfill normal distribution assumptions of $\mathrm{PO}$ and proPO, we log transformed our data. Analyses were carried out with the repeated measures module of SPSS version 21.

\section{Results}

\section{Survival}

There were differences in survival distribution for the four treatments $\left(X_{(3)}^{2}=29.12, P<0.0001\right.$; Fig. 1$)$. A comparison of both fungal treatments indicated that individuals treated with $M$. anisopliae died sooner than those treated with $I$. fumosorosea $\left(X_{(1)}^{2}=11.49, P=0.0007\right)$. For those treated with $I$. fumosorosea as well as the control groups of both fungi, no further mortality was detected after 20 days.

Imprints indicate a large invasion of both fungal species within triatomines (Figs. 2 and 3). In relation to assessment of fungal infections, cultures from the nine infected nymphs with $M$. anisopliae showed the following microscopic features: branched conidiophores with basipetal catenulate cylindrical conidia (Fig. 4a). In regards to macroscopical characteristics, initially the colony had a white color that, 


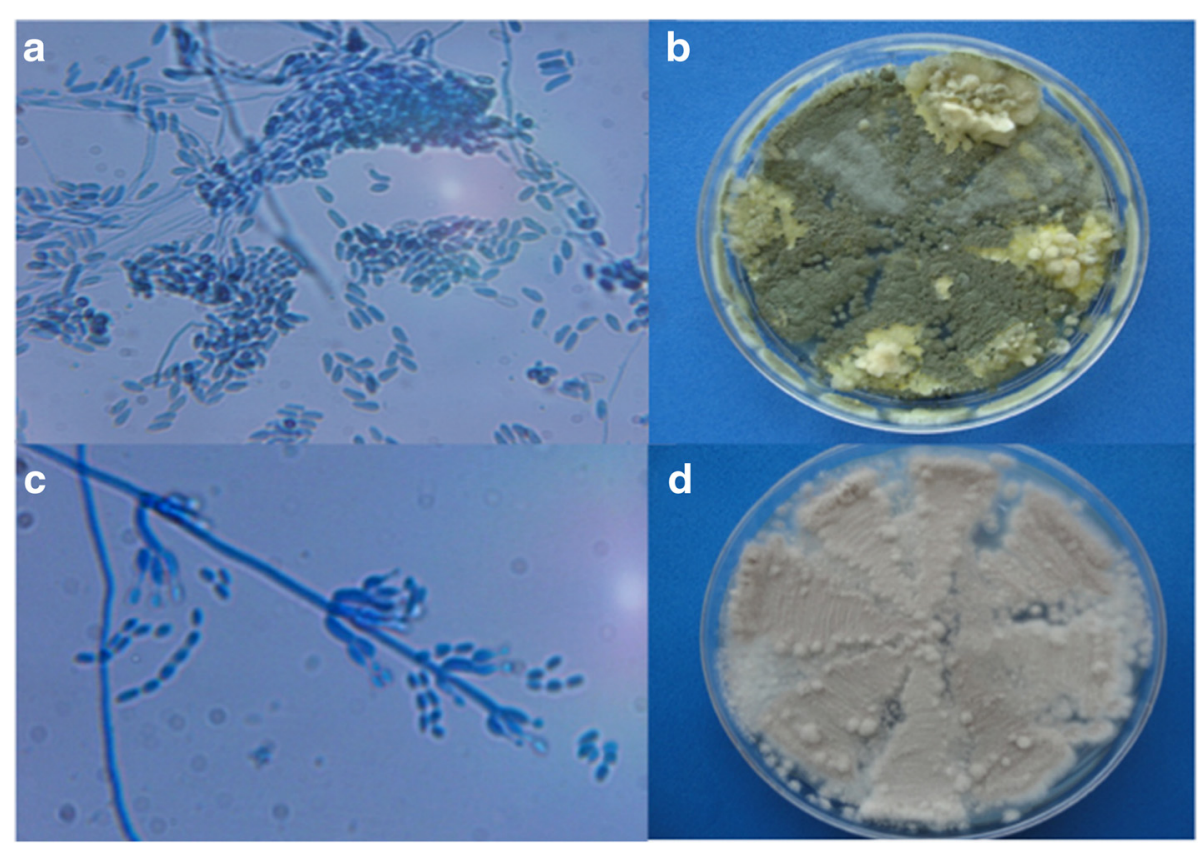

Fig. 4 Microscopic and macroscopic features after fungal growth of samples recovered from nine nymphs infected with $M$. anisopliae $(\mathrm{EH}-473 / 4 ; \mathbf{a}, \mathbf{b})$ and Isaria fumosorosea (EH- 511/3; c, d)

after several days, turned into an olive green color (Fig. 4b). Cultures from the nine infected nymphs with I. fumosorosea showed microscopic fungal features such as simple conidiophores, with a globose basal portion with emerging fusiform conidia (Fig. 4c). As for macroscopic characteristics, a typical white cotton-like colony was observed with gray-pinkish color when sporulated (Fig. 4d).

\section{PO and proPO activity according to fungal treatment Metarhizium anisopliae infection}

The general model for predicting PO changes indicated that the interaction time*treatment was significant $\left(F_{3,37}=\right.$ 11.721, $P<0.0001)$. Changes in $\mathrm{PO}$ were not significant along time $\left(F_{3,37}=0.692, P=0.563\right)$ but treatment was $\left(F_{1,39}=69.035, P<0.0001\right)$. According to the latter, $\mathrm{PO}$ showed lower values in the infected group (Fig. 5a).

The general model for proPO changes was not significant $\left(F_{3,32}=2.192, \quad P=0.108\right)$ with non-significant differences along time $\left(F_{3,32}=0.144, P=0.932\right)$ but there was a clear negative effect according to treatment $\left(F_{1,34}=31.737, P<\right.$ 0.0001 ) where the infected insects ended up with lower values than sham insects (Fig. $5 b$ ).

\section{Isaria fumosorosea infection}

There was a significant change in PO when the general model for the interaction time*treatment was examined $\left(F_{3,31}=4.812, P=0.007\right)$. Time did not predict PO changes $\left(F_{3,31}=0.522, P=0.671\right)$ but treatment did, resulting in lower values for infected insects $\left(F_{1,33}=61.072, P<0.0001\right.$; Fig. 6a).
ProPO did not show significant changes according to the interaction time"treatment $\left(F_{3,21}=2.337, P=0.103\right)$. Time did not affect proPO $\left(F_{3,21}=0.662, P=0.584\right)$ but treatment did with lower values for infected insects $\left(F_{1,23}=28.543, P<0.0001\right.$; Fig $\left.6 \mathrm{~b}\right)$.

\section{Discussion}

Our survival experiment indicated differences in killing $M$. pallidipennis, with $M$. anisopliae with a higher virulence than I. fumosorosea. As a matter of fact, the former fungus killed all animals at day 8 while the latter took longer than 30 days. These differences in the action of both fungi are likely due to a stronger effect of $M$. anisopliae when compared to I. fumosorosea. For example, M. anisopliae produces immunosuppressor toxins like destruxin [48] that may lead to damage hemocytes [49] and cause insect paralysis (via an increased calcium level in Malpighian tubules) [50]. These effects take place possibly due to the ability of $M$. anisopliae to produce a collagenous coat of hyphal bodies that mask the recognition of $\beta$-1,3-glucans by the insect immune system [51]. In contrast, little is known in regards to the effect of I. fumosorosea. It is clear that this fungus takes longer to sporulate than $M$. anisopliae, possibly due to a more paused beauvericine production [52] and hyphal growth [43]. How such effects take place via inhibition of the insect immune response, is unclear. Our results partly echo findings in other triatomines in which $M$. anisopliae was used [23, 53, 54]. To our knowledge, however, I. fumosorosea has been less extensively used against triatomines and one response 


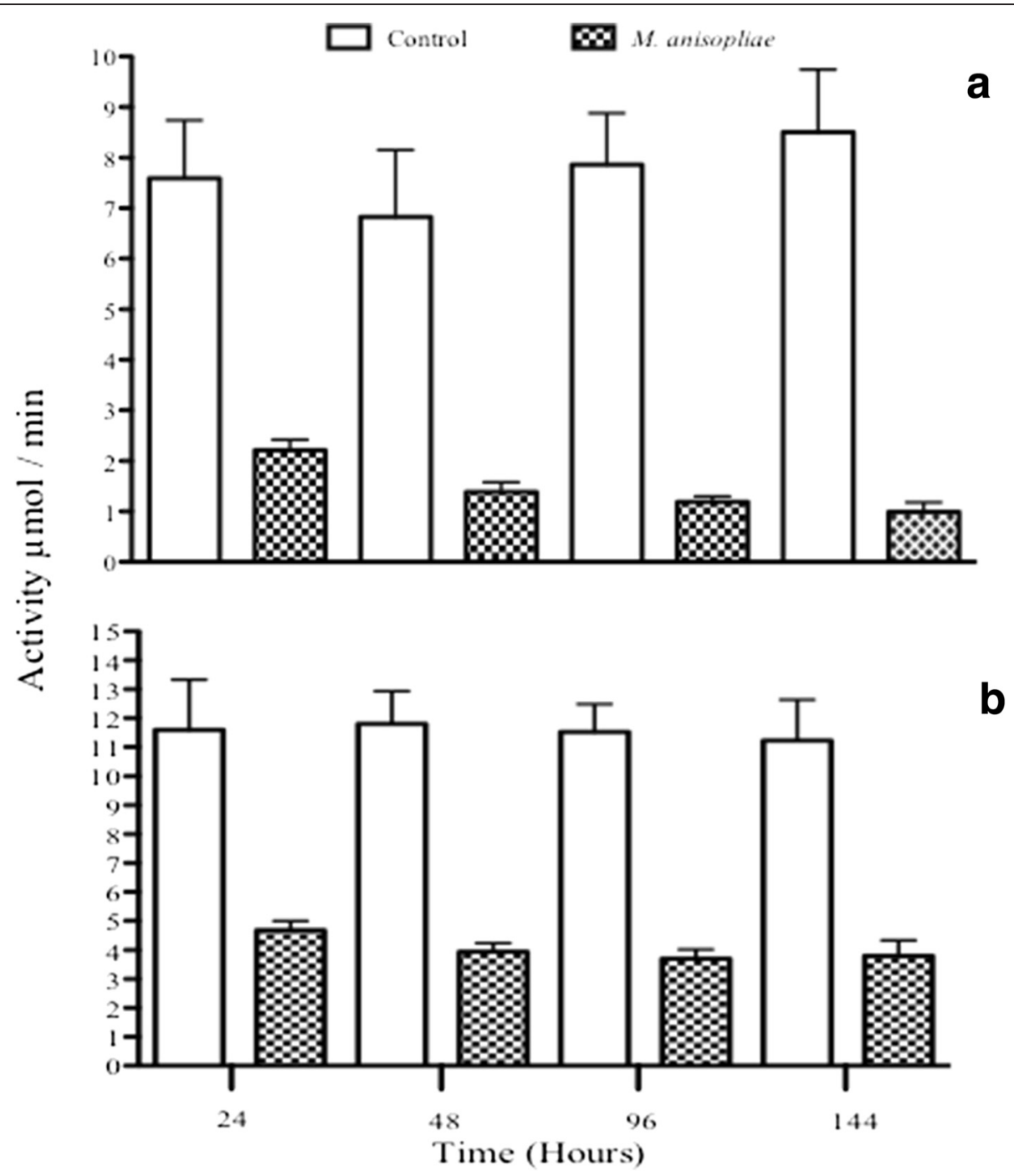

Fig. $5 \mathrm{PO}(\mathbf{a})$ and proPO (b) activity responses in fifth instar nymphs of M. pallidipennis infected with M. anisopliae (EH- 473/4) along time

may be that, as we have documented, $M$. anisopliae seems more effective. In fact, other studies in non-triatomines have corroborated that $M$. anisopliae is more effective than I. fumosorosea [55-57]. It would be interesting to compare our results with those occurring at other triatomine ages. Unfortunately, such studies have not been carried out yet.

Overall, we found that after fungal infection, both proPO and $\mathrm{PO}$ activity decreased. A first defense line in insects is that of the cuticle, where fungistatic fatty acids, phenoloxidases and melanins impede fungal penetration [58]. In case such barrier is overcome, via degradation of insect cuticle hydrocarbons [59], then the insect immune system makes use of several humoral and cellular components that include hemocytes that encapsulate fungal parts, PO, reactive oxygen species and antimicrobial peptides [60]. For the case of $\mathrm{PO}$, this synthesizes melanin whose antifungal activity acts directly on the fungal surface which stops fungal development $[36,61]$. Despite this role for PO, and its precursor, proPO, these immune components have been shown to decrease during fungal infection [29-31] although the underlying mechanism for such decrease is unclear. In relation to this, fungal infection using Beauveria bassiana in the migratory grasshopper Melanoplus sanguinipes [62] and of $M$. anisopliae in the locust Schistocerca gregaria [29, 63], led to a reduction in hemocyte number. One way this negative action can occur is via the use of fungal mycotoxins such as destruxin [48]. This compound reduces PO activity, phagocytosis and encapsulation [52]. It is unclear, however, whether such reduction accompanies or is also a function of a reduction in hemocyte number. One reason why we should expect a relation among these negative actions is that hemocytes carry out the PO cascade so that if these 


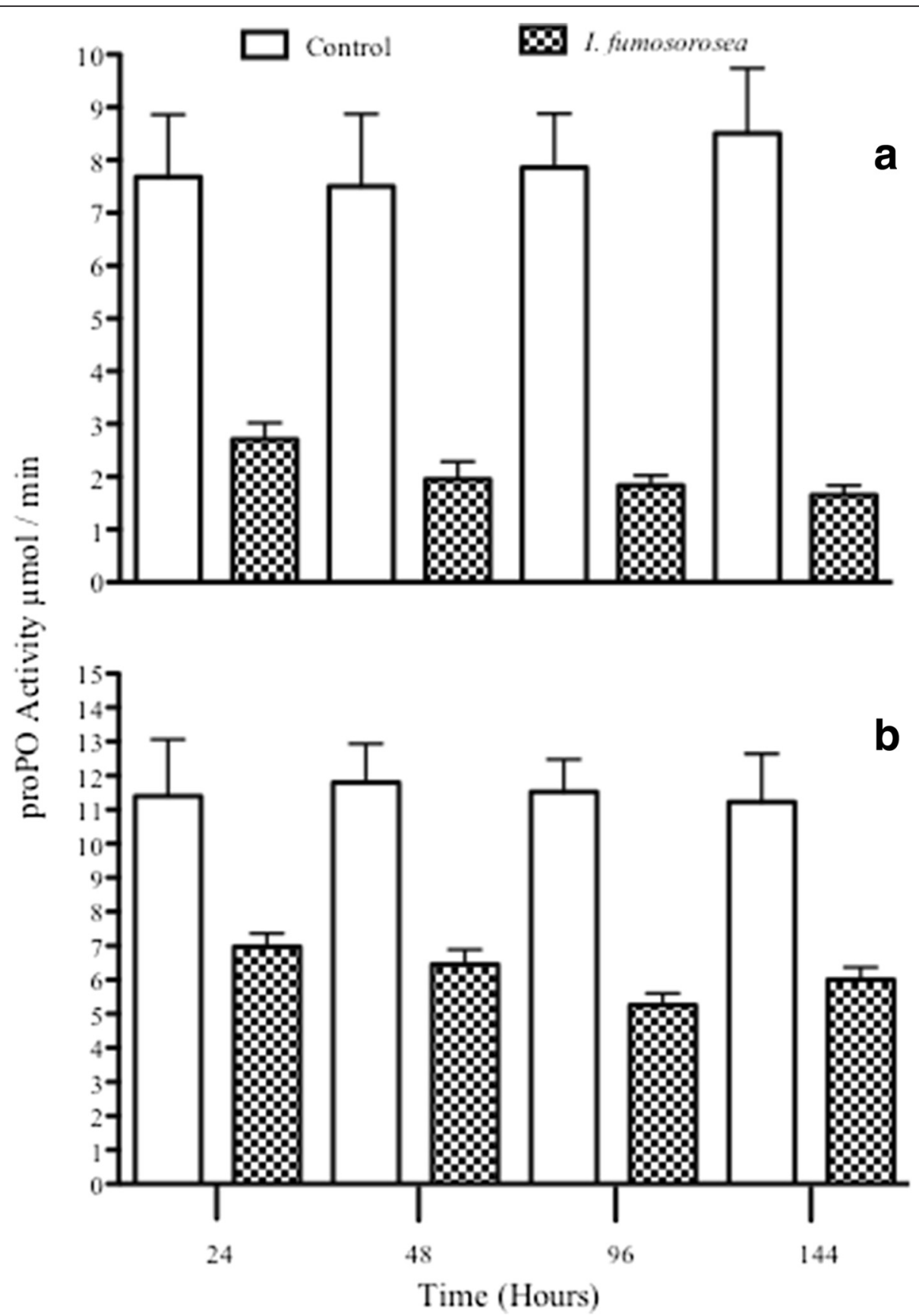

Fig. 6 PO (a) and proPO (b) activity responses in fifth instar nymphs of M. pallidipennis infected with I. fumosorosea (EH-511/3) along time

cells are affected by fungus, possibly in the form of lysis [64], proPO and PO are affected too. Furthermore, looking more closely at proPO values after infection by both fungi, this immune response showed higher activity after I. fumosorosea than after M. anisopliae treatment (Figs. 5 and 6). One has to remember that proPO is the resource tool for PO production [32] so that if both fungi had the same inhibitory $\mathrm{PO}$ response, proPO values should remain the same after the infection by either pathogen. Given the hypothesis of an inhibitory response by our fungi, the insect still makes use of some proPO for PO production after $M$. anisopliae treatment (or at least more so than after I. fumosorosea infection). This would imply that the insect shows some PO-based immune response against $M$. anisopliae so that the inhibitory response by this fungus is not as complete (or less complete) than that elicited by $I$. fumosorosea infection. This hypothesis would need further testing.

Given a first decrease in PO and proPO at $24 \mathrm{~h}$, we did not detect further changes in these immune components. 
Other studies in insects have found an initial increase in PO after 10 min of infection [64], followed by a general decrease at $24 \mathrm{~h}$ and no clear changes after this time [29, 64]. This implied an activation of an immune response followed by a negative effect of fungi on the entire PO cascade. Although we did not check what occurred soon after fungal infection, our results confirm previous claims that fungal infection affects $\mathrm{PO}$ and proPO [29-31].

Given that there are no vaccines available for controlling Chagas disease, its control relies on local preventive measures which, historically, has been based on the use of insecticides. One alternative to this chemical control is the use of entomopathogenic fungi which has been implemented in some countries [12] but not in Mexico. Our findings indeed seem promising although our conditions still prevent further implementation. For these conditions we refer, for example, to the fact that we used triatomine nymphs. It is known that effects of entomopathogenic fungi on insects may vary according to the ontogenetic insect stage used [65]. This means, that the effect of other stages in M. pallidipennis needs to be evaluated. On the other hand, perhaps the use of more than a single strategy is needed to control triatomines $[15,33]$. One way to do this is using different pathogens to which insects, or more specifically triatomines, are susceptible. Such pathogens are, for example, the bacteria Serratia marcescens $[66,67]$ Triatoma virus $[68,69]$ or, even, other fungi [33].

\section{Conclusions}

As opposed to the use of pyrethroids, entomopathogenic fungi can be used to control triatomine bugs, the vectors of Chagas disease. We showed that $M$. anisopliae fungus is actually a better control tool than I. fumosorosea for killing 5th stage nymphs of $M$. pallidipennis. Our results provide some light to such killing mechanism as, along with fungal infection, we detected a reduction in $\mathrm{PO}$ and proPO enzymes, two key components in insect immune defense. Possibly, fungi compromise immune ability via mycotoxins such as dextrusin as has been shown in other studies. Thus, our results imply an alternative tool for Chagas disease control.

\section{Competing interests}

The authors declare that they have no competing interests.

\section{Authors' contributions}

ALF-V carried out experiments, data collection and statistical analyses, laboratory analyses of immune response, drafted and revised the manuscript; MC-B provided biological material, analyses of experimental data, revised the manuscript; CT provided biological material, analyses of experimental data, revised the manuscript, MIB-T analyses of data, revised the manuscript; PMS-S participated in study design, manuscript drafting and revision; AC-A participated in study design, statistical analyses, manuscript drafting and revision. All authors read and approved the final version of the manuscript.

\section{Acknowledgements}

A. Laura Flores-Villegas acknowledges the scholarship and financial support provided by the Consejo Nacional de Ciencia y Tecnología (CONACyT-326511) as well as logistic support from the Posgrado en Ciencias Biológicas (UNAM). This paper constitutes a partial fulfillment of the doctoral work of A. Laura Flores-Villegas in the Posgrado en Ciencias Biológicas of the Universidad Nacional Autónoma de México. We thank M.O. Vences-Blanco for the support in rearing insects. Thanks to R. I. Martínez-Becerril for logistic support. To the Faculty of Medicine (UNAM) for partial financial support to MC-B, MIB-T and PMS-S. CT and AC-A were supported by DGAPA-PAPIIT grants IT202012 and IN203115

(UNAM) respectively. Finally, all co-authors have no conflict of interest.

Received: 22 January 2016 Accepted: 15 March 2016

Published online: 24 March 2016

\section{References}

1. Steverding D. The history of Chagas. Parasit Vectors. 2014;7:317.

2. Schmunis GA, Yadon ZE. Chagas disease: a Latin American health problem becoming a world health problem. Acta Trop. 2010;115:14-21.

3. Martínez-Ibarra JA, Nogueda-Torres B, García-Benavídes G, Vargas-Llamas V, Bustos-Saldaña R, Montañez-Valdez OD. Bionomics of populations of Meccus pallidipennis (Stal), (Hemiptera: Reduviidae) from Mexico. J Vect Ecol. 2012; 37:474-7.

4. Carcavallo RU, Galíndez-Girón I, Jurberg J, Galvao C, Lent H. Bibiographic checklist of the American triatominae (Hemiptera: Reduviidae). In: Carcavallo R, Galíndez-Girón I, Jurberg J, Lent H, editors. Atlas of Chagas Disease Vectors in the Americas, Vol. I. Rio de Janeiro: Editora Fiocruz; 1997. p. 15-52

5. Salazar-Schettino PM, Rojas-Wastavino E, Cabrera-Bravo M, Bucio-Torres M, Martínez-Ibarra JA, Monroy-Escobar MC, Rodas-Retana A, Guevara-Gómez Y, Vences-Blanco MO, Ruíz-Hernández AL, Torres-Gutiérrez E. A revision of thirteen species of Triatominae (Hemiptera: Reduviidae) vectors of Chagas disease in Mexico. J Selva Andina Res Society. 2010;1:57-80.

6. Martínez-Ibarra JA, Grant-Guillén Y, Morales-Corona ZY, Haro-Rodriguez S, Ventura-Rodríguez LV, Nogueda-Torres B, Bustos-Saldaña R: Importance of species of Triatominae (Heteroptera: Reduviidae) in risk of transmission of Trypanosoma cruzi in western Mexico. J Med Entomol. 2008;45:476-82.

7. Benítez-Alva Jl, Huerta H, Téllez-Rendón JL. Distribución de triatominos (Heteroptera: Reduviidae) asociados a la vivienda humana y posibles zonas de riesgo en seis estados de la República Mexicana. BIOCYT: Biología Ciencia y Tecnología. 2012:5:327-40.

8. Martínez-lbarra JA, López MN. Blood meals to molt, feeding time and postfeeding defecation delay of Meccus pallidipennis (StÅl, 1872) (Hemiptera: Reduviidae) under laboratory conditions. Folia Entomol Mex. 1872;2004(43):313-9.

9. Ramsey JM, Cruz-Celis A, Salgado A, Espinosa L, Ordoñez R, Lopez R, Schofield CJ: Efficacy of pyrethroid insecticides against domestic and peridomestic populations of Triatoma pallidipennis and Triatoma barberi (Reduviidae: Triatominae) vector of Chagas disease in Mexico. J Med Entomol. 2003:40:912-20.

10. Gorla DE, Ortiz RV, Catalá SS. Control of rural house infestation by Triatoma infestans in the Bolivian Chaco using a microencapsulated insecticide formulation. Parasit Vectors. 2015:8:255.

11. Mougabure-Cueto G, Picollo MI. Insecticide resistance in vector Chagas disease: evolution, mechanisms and management. Acta Tropi. 2015;149:70-85.

12. Pedrini N, Mijailovsky SJ, Girotti JR, Stariolo R, Cardozo RM, Gentile A, Juárez MP: Control of pyrethroid-resistant Chagas disease vectors with entomopathogenic fungi. PLoS Negl Trop Dis. 2009;3:e434.

13. Beard CB, Cordon-Rosales C, Durvasula RV. Bacterial symbionts of the triatominae and their potential use in control of Chagas disease transmission. Annu Rev Entomol. 2002;47:123-41.

14. Linares G, Caicedo R. Pimeliaphilus triatomae (Acari: Pteregosomidae) utilizado como control biológico de Meccus pallidipennis (Hemiptera: Reduviidae) en condiciones de laboratorio. Rev Colomb Entomol. 2004;30:131-5.

15. Gürtler RE, Yadon ZE. Eco-biosocial research on community-based approaches for Chagas disease vector control in Latin America. Trans R Soc Trop Med Hyg. 2015:109:91-8.

16. Lee SJ, Kim S, Yu JS, Kim JC, Nai YS, Kim JS. Biological control of Asian tiger mosquito, Aedes albopictus (Diptera: Culicidae) using Metarhizium anisopliaeJEF-003 millet grain. J Asia Pacific Entomol. 2015;18:217-21.

17. Webster A, Reck J, Santi L, Souza UA, Dall'Agnol B, Klafke GM, Beys-da-Silva WO, Martins JR, Schrank A: Integrated control of an acaricide-resistant strain of the cattle tick Rhipicephalus microplus by applying Metarhizium anisopliae associated with cypermethrin and chlorpyriphos under field conditions. Vet Parasitol. 2015;207:302-8. 
18. Patt JM, Chow A, Meikle WG, Garcia C, Jackson MA, Flores D, Sétamou M, Dunlap CA, Avery PB, Hunter WB, Adamczyk JJ: Efficacy of an autodisseminator of an entomopathogenic fungus, Isaria fumosorosea, to suppress Asian citrus psyllid, Diaphorina citri, under greenhouse conditions. Biol Control. 2015;88:37-45.

19. Nian XG, He YR, Lu LH, Zhao R. Evaluation of alternative Plutella xylostella control by two /saria fumosorosea conidial formulations-oil-based formulation and wettable powder-combined with Bacillus thuringiensis. Pest Manag Sci. 2015;71:1675-84

20. Romaña CA, Fargues J. Relative susceptibility of different stages of Rhodnius prolixus to the entomopathogenichyphomycete Beauveria bassiana. Mem Inst Oswaldo Cruz. 1992;87:363-8.

21. Juárez MP, Crespo R, Calderón-Fernández G, Lecuona RE, Cafferata LFR. Characterization and carbon metabolism in fungi pathogenic to Triatoma infestans, a Chagas disease vector. J Invertebr Pathol. 2000;76:198-207.

22. Lecuona RE, Edelstein JD, Berretta MF, La Rossa FR, Arcas JA. Evaluation of Beauveria bassiana (hyphomycetes) strains as potential agents for control of Triatoma infestans (Hemiptera: Reduviidae). J Med Entomol. 2001;38:72-179.

23. Rodrigues J, Lobo LS, Fernandes É, Luz C. Effect of formulated Metarhizium anisopliae on eggs and eclosing nymphs of Triatoma infestans. J Appl Entomol. 2015;139:146-53.

24. Blandford S, Chan BH, Jenkins N, Sim D, Turner RJ, Read AF, Thomas MB: Fungal pathogen reduces potential for malaria transmission. Science. 2005; 308:1638-41.

25. Forlani N, Pedrini N, Girotti JR, Mijailovsky SJ, Cardozo RM, Gentile AG, Hernández-Suárez CM, Rabinovich JE, Juárez MP: Biological control of the Chagas disease vector Triatoma infestans with the entomopathogenic fungus Beauveria bassiana combined with an aggregation cue: field, laboratory and mathematical modeling assessment. PLoS Negl Trop Dis. 2015;9:e0003778

26. Boucias DG, Pendland JC. The fungal cell wall and its involvement in the pathogenic process in insects hosts. In: Latgé JP, Boucias D, editors. Fungal Cell Wall and Immune Response. Berlin: Springer; 1991. p. 303-16.

27. Charnley AK, St. Leger RJ. The role of cuticle degrading enzymes in fungal pathogenesis in insects. In: Cole TG, Hoch $\mathrm{CH}$, editors. The fungal Spore and Disease Initiation in Plants and Animals. New York: Plenum Press; 1991. p. 267-86.

28. Thomas MB, Read AF. Can fungal biopesticides control malaria? Nat Rev Microbiol. 2007;5:377-83.

29. Gillespie JP, Burnett C, Charnley AK. The immune response of the desert locust Schistocerca gregaria during mycosis of the entomopathogenic fungus, Metarhizium anisopliae var acridum. J Insect Physiol. 2000;46:429-37.

30. Bogus'MI, Kendra E, Bania J, Szczepanik M, Czygier M, Jablonsky P, Pasztaleniec A, Samborski J, Mazgajska J, Polanowski A. Different defense strategies of Dendrolimus pini, Galleria mellonella, and Calliphora vicina against fungal infection. J Insect Physiol. 2007;53:909-22.

31. Khosravi $R$, Sendi JJ, Zibaee A, Shokrgozar MA. Immune reactions of the lesser mulberry pyralid, Glyphodes pyloalis Walker (Lepidoptera: Pyralidae) to the entomopathogenic fungus, Beauveria bassiana (Bals.-Criv.) Vuill and two developmental hormones. Invert Surviv J. 2014;11:11-21.

32. González-Santoyo IG, Córdoba-Aguilar. Phenoloxidase: a key component of the insect immune system. Entom Exp Appl. 2012;142:1-16.

33. Flores-Villegas AL, Salazar-Schettino PM, Córdoba-Aguilar A, Gutiérrez-Cabrera AE, Rojas-Wastavino GE, Bucio-Torres MI, Cabrera-Bravo M: Immune defence mechanisms of triatomines against bacteria, viruses, fungi and parasites. Bull Entomol Res. 2015;105:523-32.

34. Laughton AM, García JR, Altincieck B, Strand MR, Gerardo NM. Characterisation of immune responses in the pea aphid, Acyrthosiphon pisum. J Insect Physiol. 2011:57:830-9.

35. Smilanich AM, Dyer LA, Gentry GL. The insect immune response and other putative defenses as effective predictors of parasitism. Ecology. 2009:90:1434-40.

36. Cerenius L, Thörnqvist PO, Vey A, Johansson MW, Söderhall K. The effect of the fungal toxin destruxin $E$ on isolated crayfish haemocytes. J Insect Physiol. 1990:36:785-9.

37. Park SY, Kim CH, Jeong WH, Lee Jh, Seo SJ, Han YS, Lee IH: Effects of two hemolymph proteins on humoral defense reactions in the wax moth, Galleria mellonella. Dev Comp Immunol. 2005;29:43-51.

38. Toriello C. Bioseguridad de Metharhizium anisopliae (Metschnikoff) Sorokin (Hyphomycete). Vedalia. 2003;10:107-13.

39. Toriello C, Pérez-Torres A, Burciaga-Díaz A,Navarro-Barranco H, Pérez-Mejía A, Lorenzana Jiménez M, Mier T: Lack of acute pathogenicity and toxicity in mice of an isolate of Metarhizium anisopliae var. anisopliae from spittlebugs. Ecotoxicol Environ Saf. 2006;65:278-87.
40. Toriello C, Montoya-Sansón E, Zavala-Ramírez M, Navarro-Barranco H, BasilioHernández D, Hernández-Velázquez V, Mier T: Virulencia y termotolerancia de cultivos monospóricos de Metarhizium anisopliae var. anisopliae de la mosca pinta (Hemiptera: Cercopidae). Rev Mex Micol. 2008;28:57-66.

41. Mier T, Toriello C, Ulloa M. Hongos microscópicos saprobios y parásitos: métodos de laboratorio. México: UAM Xochimilco, Instituto de Biología; 2002

42. Goettel MS, Inglis SD. Fungi: Hyphomycetes. In: Lacey LA, editor. Manual of techniques in insect pathology. Londres: Academic; 1997. p. 213-48.

43. Castellanos-Moguel J, Mier, T, Reyes-Montes MR, Navarro-Barranco H, ZepedaRodriguez A, Pérez-Torres A, Toriello, C: Fungal growth development index and ultrastructural study of whiteflies infected by three Isaria fumosorosea isolates of different pathogenicity. Rev Mex Micol. 2013;38:23-33.

44. Espinosa de Aquino W. Estudio de moléculas del sistema inmune de Triatoma pallidipennis infectado con Trypanosoma cruzi. Mexico City, Mexico: Tesis de Maestría en Ciencias, UNAM, 2012

45. Córdoba-Aguilar A, Ruiz-Silva D, Munguía-Steyer R, Lanz-Mendoza H. Do reproductive activities compromise immunological competence as measured by phenoloxidase activity? Field and experimental manipulation in females of two damselfly species. Physiol Entomol. 2011;36:335-42.

46. Laughton AM, Siva-Jothy MT. A standarised protocol for measuring phenoloxidase and prophenoloxodase in the honey bee, Apis mellifera. Apidologie. 2010;42:140-9.

47. Jiménez-Cortés JG, Serrano-Meneses MA, Córdoba-Aguilar A. The effects of food shortage during larval development on adult body size, body mass, physiology and developmental time in a tropical damselfly. J Insect Physiol. 2012;58:318-26.

48. Avulova S, Rosengaus RB. Losing the battle against fungal infection: suppression of termite immune defenses during mycosis. J Insect Physiol. 2011;57:966-71.

49. Kershaw MJ, Moorhouse ER, Bateman R, Reynolds SE, Charnley AK. The role of destruxins in the pathogenicity of Metarhizium anisopliae for three species of insect. J Invertebr Pathol. 1999;74:213-23.

50. Ruiz-Sanchez E, Orchard I, Lange AB. Effect of the cyclopeptide mycotoxin destruxin A on the Malpighian tubules of Rhodnius prolixus (Stal). Toxicon. 2010;55:1162-70.

51. Wang C, St. Leger RJ. A collagenous protective coat enables Metarhizium anisopliae to evade insect immune responses. Proc Nat Acad Sci USA. 2006; 103:6647-52.

52. Rohlf M, Churchill AC. Fungal secondary metabolites as modulators of interactions with insects and other arthropods. Fungal Genet Biol. 2011; 48:23-34

53. Luz C, Rodrigues J, Rocha LF. Diatomaceous earth and oil enhance effectiveness of Metarhizium anisopliae against Triatoma infestans. Acta Trop. 2012;122:29-35.

54. Murerwa P, Arama PF, Kamau AW, Maniania NK. Effect of infection by Metarhizium anisopliae isolate ICIPE 51 on developmental stage, fecundity and intrinsic rate of increase of Rhopalosiphum padi and Metopolophium dirhodum. J Entomol Nematol. 2014;6:154-60.

55. Flores A, Pucheta M, Rodriguez S. Mycoinsecticide effects of Beauveria bassiana, Metarhizium anisopliae, and Isaria fumosorosea on the whitefly Bemisia tabaci (Homoptera: Aleyrodidae) in different strata of bean. Afr J Microbiol Res. 2012;6:7246-52.

56. Kavallieratos NG, Athanassiou CG, Aountala MM, Kontodimas DC. Evaluation of the entomopathogenic fungi Beauveria bassiana, Metarhizium anisopliae, and Isaria fumosorosea for control of Sitophilus oryzae. J Food Prot. 2014;77: 87-93.

57. Sajap AS, Rozihawati Z, Omar D, Lau WH. Isaria fumosorosea and Metarhizium anisopliae for controlling Atteva sciodoxa (Lepidoptera: Yponomeutidae), a pest of Eurycoma longifolia. J Trop For Sci. 2014;26:84-91.

58. Wraight SP, Butt TM, Galaini-Wraight S, Allee LL, Soper RS, Roberts DW. Germination and infection processes of the entomophthoralean fungus Erynia radicans on the potato leafhopper, Empoasca fabae. J Invertebr Pathol. 1990;56:157-74

59. Napolitano R, Juárez MP. Entomopathogenous fungi degrade epicuticular hydrocarbons of Triatoma infestans. Arch Biochem Biophys. 1997;344:208-14.

60. Yan XD, Scherphof GL, Kamps J. Liposomeopsonization. J Liposome Res. 2005;15:109-39. doi:10.1081/lpr-200064971.

61. Butt TM, Wraight SP, Galaini-Wraight S, Humber RA, Roberts DW, Soper RS. Humoral encapsulation of the fungus Erynia radicans (Entomophthorales) by the potato leafhopper, Empoasca fabae (Homoptera: Cicadellidae). J Invertebr Pathol. 1988:52:49-56. 
62. Bidochka MJ, Khachatourians GC. Hemocytic defense response to the entomopathogenic fungus Beauveria bassiana in the migratory grasshopper Melanoplus sanguinipes. Entomol Exp Appl. 1987;45:151-6.

63. Milat-Bissaad FZ, Bounaceur F, Halouane F, Behidj N, Chebouti N, Doumandji Mitiche B. Effect of entomopathogenic fungi Beauveria bassiana and Metarhizium anisopliae var. acridum on the haemolymph of the desert locust Schistocerca gregaria. Tunis J Plant Prot. 2011;6:127-32.

64. Gillespie JP, Khachatourians GG. Characterization of the Melanoplus sanguinipes hemolymph afer infection with Beauveria bassiana or wounding. Comp Biochem Physiol. 1992;103:445-63.

65. Mullen LM, Goldsworthy GJ. Immune responses of locusts to challenge with the pathogenic fungus Metarhizium or high doses of laminarin. J Insect Physiol. 2006;52:389-98.

66. Azambuja P, Feder D, Garcia ES. Isolation of Serratia marcescens in the midgut of Rhodnius prolixus: impact on the establishment of the parasite Trypanosoma cruzi in the vector. Exp Parasitol. 2004;107:89-96.

67. Gourbière S, Dorn P, Tripet F, Dumonteil F. Genetics and evolution of triatomines: from phylogeny to vector control. Heredity. 2012;108:190-202.

68. Muscio OA, La Torre JL, Scodeller EA. Small nonoccluded viruses from triatominae bug Triatoma infestans (Hemiptera: Reduviidae). J Invertebr Pathol. 1987:49:218-20.

69. Muscio OA, La Torre JL, Bonder MA, Scodeller EA. Triatoma virus pathogenicity in laboratory colonies of Triatoma infestans (Hemiptera: Reduviidae). J Med Entomol. 1997:34:253-6.

\section{Submit your next manuscript to BioMed Central and we will help you at every step:}

- We accept pre-submission inquiries

- Our selector tool helps you to find the most relevant journal

- We provide round the clock customer support

- Convenient online submission

- Thorough peer review

- Inclusion in PubMed and all major indexing services

- Maximum visibility for your research 